\title{
Serotonin and Cyclic GMP Both Induce an Increase of the Calcium Current in the Same Identified Molluscan Neurons
}

\author{
Danièle Paupardin-Tritsch, Constance Hammond, ${ }^{1}$ and Hersch M. Gerschenfeld \\ Laboratoire de Neurobiologie, Ecole Normale Supérieure, 75230 Paris Cedex 05, France
}

Serotonin (5-HT) has previously been shown to evoke an increase in the duration of the $\mathrm{Ca}^{2+}$-dependent spike of molluscan neurons by decreasing the $S$ current (Klein et al., 1982), a $\mathrm{K}^{+}$ current controlled by cAMP. However, in a group of identified ventral neurons of the snail Helix aspersa in which 5-HT (1-10 $\mu \mathrm{M})$ also prolonged the duration of the $\mathrm{Ca}^{2+}$-dependent action potential, no 5-HT-induced depression of $S$ current or of any other outward current was observed. Instead, 5-HT was found to evoke the prolongation of the somatic spike by inducing an increase in $\mathrm{Ca}^{2+}$ membrane conductance. This 5-HT-induced increase of $\mathrm{Ca}^{2+}$-current was mimicked neither by the intracellular injection of cAMP nor by the extracellular application of forskolin (20 $\mu \mathrm{M})$. In contrast, it was mimicked by the intracellular injection of cGMP and by the extracellular application of $100 \mathrm{nM}$ zaprinast, a cGMP-phosphodiesterase inhibitor. The extracellular application of phorbol ester TPA (100 nM), an activator of protein kinase $C$, was also found to increase the $\mathrm{Ca}^{2+}$ current in the identified snail ventral neurons, but this enhancing effect had a different time course from that induced by 5-HT. These results indicate that there is a second mechanism for prolonging the $\mathrm{Ca}^{2+}$ spike of molluscan neurons, consisting of an increase in $\mathrm{Ca}^{2+}$ current, in which cGMP may play a role as second messenger.

Two different mechanisms of transmitter-induced increase of the duration of the calcium action potential have been described in excitable cells. The first occurs in both amphibian and mammalian cardiac muscle fibers. In these cells, the stimulation of beta-adrenergic receptors causes an increase in the duration of the action potential by increasing the $\mathrm{Ca}^{2+}$ current (Reuter, 1983; Reuter and Scholz, 1977; Tsien, 1983; Vassort et al., 1969). This effect is mimicked by the application of cAMP and its analogs (see Brum et al., 1983; Reuter et al., 1983; Tsien, 1977), as well as by the intracellular injection of the catalytic unit of a cAMP-dependent protein kinase (Brum et al., 1983; Osterrieder et al., 1982). Patch-clamp studies reveal that the betaadrenergic stimulation of cardiac muscle cells actually evokes an increase in the number of functional $\mathrm{Ca}^{2+}$ channels (Bean et al., 1984; Reuter et al., 1983) and a slowing down of the time course of both the activation and inactivation of these channels (Bean et al., 1984; Brum et al., 1984).

The second mechanism of transmitter-induced increase of the

\footnotetext{
Received Nov. 11, 1985; revised Feb. 5, 1986; accepted Feb. 17, 1986.

This work was supported by grants from the Centre National de la Recherche Scientifique, France (UA 295 and ATP Pharmacologie de la Neurotransmission) and from the Ministère de la Recherche et de la Technologie, France (Grant 83 C0914). We thank Dr. A. Ishida and Dr. P. Ascher for reviewing the manuscript.

Correspondence should be addressed to Dr. H. M. Gerschenfeld, Laboratoire de Neurobiologie, Ecole Normale Supérieure, 46 Rue d'Ulm, 75230 Paris Cedex 05 , France.

I Present address: Laboratoire de Physiologie, C.H.U. Pitič-Salpêtrière, 91 Boulevard de l'Hôpital, 75634 Paris Cedex 13, France.

Copyright (C) 1986 Society for Neuroscience $0270-6474 / 86 / 092715-09 \$ 02.00 / 0$
}

calcium spike duration was observed in molluscan neurons. Here, serotonin (5-hydroxytryptamine, 5-HT), dopamine, and some cardiocxcitatory peptides $\left(\mathrm{SCP}_{\mathrm{A}}\right.$ and $\left.\mathrm{SCP}_{\mathrm{B}}\right)$ have no direct effect on the $\mathrm{Ca}^{2+}$ current (Abrams et al., 1984; Klein and Kandel, 1978, 1980; Paupardin-Tritsch et al., 1981, 1985a, b). Instead, for example, 5-HT was found to increase the calcium spike duration of sensory neurons in Aplysia californica and of identified neurons in Helix aspersa by evoking a decrease in a $\mathrm{K}^{+}$conductance (Klein and Kandel, 1978, 1980; PaupardinTritsch et al., 1981). This effect is mimicked by either the intracellular injection of cAMP or by agents that increase intracellular cAMP concentration (Deterre et al., 1981, 1982; Klein and Kandel, 1978, 1980). A similar increase in the duration of the action potential in Aplysia neurons can also be evoked by the intracellular injection of the catalytic unit of a cAMP-dependent protein kinase (Castellucci et al., 1982; Kaczmarek et al., 1980). Patch-clamp study of sensory Aplysia neurons has revealed that both 5-HT and cAMP elicit the closing of a population of "background" $\mathrm{K}^{+}$channels (called the $\mathrm{S}$ channels), which constitute the predominant channel population when these cells are held at potentials near $0 \mathrm{mV}$ (Siegelbaum et al., 1982). The application of the catalytic unit of a cAMP-dependent protein kinase to inside-out membrane patches from the same neurons also closes the $\mathrm{S}$ channels (Shuster et al., 1985). In voltageclamped Aplysia sensory neurons, the closing of the $\mathrm{S}$ channels by 5-HT is reflected in the decrease of a specific outward current component, the $S$ current (Klein et al., 1982). 5-HT, dopamine, and the neuropeptide FMRF-amide are also able to decrease the $\mathrm{S}$ current of identified snail neurons (Colombaioni et al., 1985; Paupardin-Tritsch et al., 1985a, b, and unpublished observations).

The possibility that 5-HT might also increase the $\mathrm{Ca}^{2+}$ current in some molluscan neurons was recently suggested by 2 different findings in Aplysia. On one hand, Pellmar (1984) observed that 5-HT increases the inward current recorded in the RB neurons of Aplysia bathed in seawater containing both tetraethylammonium chloride (TEA) and 4-aminopyridine (4-AP) and in which $\mathrm{Ca}^{2+}$ was replaced by $\mathrm{Ba}^{2+}$. On the other hand, Boyle et al. (1984) showed that besides decreasing the S current, 5-HT could also evoke an increase in the intracellular $\mathrm{Ca}^{2+}$ concentration in the Aplysia sensory cells; this effect could be due either to an increase in $\mathrm{Ca}^{2+}$ influx or to a redistribution of intracellular $\mathrm{Ca}^{2+}$.

In the present work, we have investigated the effects of 5-HT on a group of identified neurons located on the ventral face of the parietal ganglion of the snail $H$. aspersa. In these cells, 5-HT increased the somatic spike duration but did not evoke any slow inward current when the cells were held at potentials between 0 and $+20 \mathrm{mV}$. In these neurons, 5-HT was found to evoke only an increase in inward current, resulting from an increase in $\mathrm{Ca}^{2+}$ membrane conductance. This action of 5-HT was mimicked neither by cAMP nor by forskolin. In contrast, it was mimicked by both the extracellular application of phorbol ester 


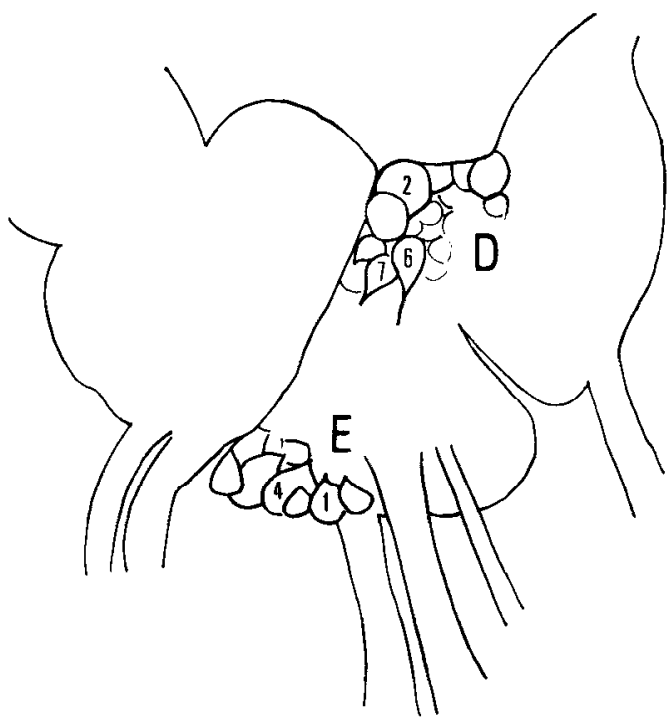

Figure 1. Localization of the identified snail ventral neurons. Schematic view of the ventral face of the viscero-abdominal ganglionic mass of $H$. aspersa. The nomenclature of Kerkut et al. (1975) has been used: $D$, left parietal ganglion; $E$, visceral ganglion. The identified neurons are denominated by the ganglion letter plus a number: D6, D7, etc.

TPA, a protein kinase C activator (see DeRiemer et al., 1985) and the intracellular injection of cyclic $3^{\prime}, 5^{\prime}$-guanosine monophosphate (cGMP). The increase in the $\mathrm{Ca}^{2+}$ current induced by phorbol ester TPA had a different time course from that evoked by 5-HT. Zaprinast, an inhibitor of the cGMP-phosphodiesterase (see Winquist et al., 1984), also increased the $\mathrm{Ca}^{2+}$ current of the identified snail neurons.

From these results it can be concluded that 5-HT can also evoke an increase in the duration of the somatic $\mathrm{Ca}^{2+}$-dependent action potential of identified molluscan neurons by increasing the membrane $\mathrm{Ca}^{2+}$ conductance. In contrast to the transmitterinduced increase of $\mathrm{Ca}^{2+}$ current in cardiac muscle cells, the 5-HT-induced increase of the $\mathrm{Ca}^{2+}$ current is not mediated by cAMP. The present results suggest that cGMP may be the second messenger mediating the 5-HT-induced increase of $\mathrm{Ca}^{2+}$ current.

Some of these results were previously reported in a preliminary form (Paupardin-Tritsch et al., 1985a).

\section{Materials and Methods}

The electrophysiological experiments were performed on a group of identified neurons of the ventral face of the left parietal ganglion of the snail $H$. aspersa. These neurons (D6, D7) could be recognized in different preparations by their position-Figure 1 (Kerkut et al., 1975)and in the present paper they will be referred to as "identified ventral parietal neurons." Neuron E1 located in the visceral ganglion (Fig. 1) showed the same features as neurons D6 and D7.

The experiments were performed on the snail perioesophagic ganglionic ring, isolated and fixed inside a plastic chamber exposing the ventral face of the visceroabdominal ganglia. The glioconnective envelope of these ganglia was extensively removed under microscopic visualization. The preparation was bathed in a continuously circulating saline solution with the following composition (in $\mathrm{mm} /$ liter): $\mathrm{NaCl}, 120 ; \mathrm{KCl}, 2.5$; $\mathrm{CaCl}_{2}, 6 ; \mathrm{MgCl}_{2}, 3.5$; and HEPES, $10 ; \mathrm{pH}$ 7.4. The bath was connected to earth through an agar bridge.

The identified ventral parietal neurons were voltage-clamped using a 2-microelectrode system. The pipettes were filled with $3 \mathrm{M} \mathrm{KCl}$ and had resistances of 1-5 MR. The transmembrane voltages and the clamping currents were recorded simultaneously on a Tektronix oscilloscope, a Gould pen recorder, and a Racal 4 magnetic tape recorder.

The $I-V$ curves were obtained by holding the neuron membrane potential at $-50 /-60 \mathrm{mV}$ and then depolarizing the cell using pulses
50 or $60 \mathrm{msec}$ long. In tracing the $I-V$ curves for the $\mathrm{Ca}^{2+}$ currents, the current responses to equivalent hyperpolarizing pulses were added to cancel linear leakage. In other experiments, the membrane potential of the neurons was held at $+10 \mathrm{mV}$ and the effects of 5-HT examined.

5-HT-creatinine sulfate was dissolved in saline and applied through the circulating system. For each experiment, a fresh solution was used and its $\mathrm{pH}$ controlled. EGTA, cAMP, and cGMP were injected intracellularly from single micropipettes either by pressure or iontophoresis. In the latter case, appropriate currents were passed between the barrels of a double microelectrode. One of the barrels was filled with aqueous solutions of $0.25 \mathrm{M} \mathrm{K}_{2}$-EGTA or $0.1 \mathrm{M}$ cAMP monosodium salt or 0.1 $\mathrm{M}$ cGMP monosodium salt, and the other barrel with $3 \mathrm{M} \mathrm{KCl}$. For pressure injection, the 3 agents were dissolved at the same concentrations in a solution containing $60 \mathrm{mM} \mathrm{KCl}$ and $1 \mathrm{mM}$ HEPES.

In many experiments, the extracellular ionic concentration was modified: The extracellular $\mathrm{Ca}^{2+}$ concentration was totally replaced by either $\mathrm{Mg}^{2+}$ or $\mathrm{Ba}^{2+}$. TEA chloride was added to the saline by substituting it for an equimolar amount of $\mathrm{NaCl}$. TTX, 4-AP, isobutylmethylxanthine (IBMX), and zaprinast (compound M\&B22948, see Winquist et al., 1984) were dissolved in the circulating saline. Phorbol ester TPA (12$O$-tetradecanoyl-phorbol-13-acetate) was dissolved in the absolute ethanol $(1 \mathrm{mg} / \mathrm{ml})$ and then further dissolved in saline. Forskolin was first dissolved in absolute alcohol to prepare a $20 \mathrm{~mm}$ stock solution and then diluted in the saline.

\section{Nystatin experiments}

These experiments were performed following the protocol established by Tillotson (1979). The neurons were first bathed for $30 \mathrm{~min}$ in a " $\mathrm{Cs}^{+}$ loading" solution containing the following (in mM/liter): $\mathrm{CsCl}, 60 ; \mathrm{MgCl}_{2}$, 9.5; sucrose, 130; HEPES, 10 (pH 7.4), and nystatin, $50 \mathrm{mg} /$ liter. The preparation was then washed in the same solution without nystatin for another $30 \mathrm{~min}$. After this, the neurons were bathed in a solution containing the following (mM/liter): $\mathrm{NaCl}$ or Tris-Cl, 90; TEA, 30; $\mathrm{CsCl}$ $5 ; \mathrm{MgCl}_{2}, 3.5 ; \mathrm{BaCl}_{2}, 6$; and HEPES, $10(\mathrm{pH} \mathrm{7})$. In these experiments the micropipettes for recording voltage and current were always filled with $1 \mathrm{M}$ CsCl.

\section{Results}

\section{Effects of 5-HT on identified ventral parietal neurons of $\mathrm{H}$. aspersa}

\section{Effects of 5-HT on the calcium-dependent action potential}

Figure $2 A$ illustrates the effects of the extracellular application of 5-HT on the action potential recorded in the soma of a D6 neuron bathed in saline containing $30 \mathrm{~mm}$ TE.A. Under these conditions, the blockade of some of the $\mathrm{K}^{+}$conductance components by TEA unmasks a rather large $\mathrm{Ca}^{2+}$-dependent plateau phase (Fig. 2A, control). The addition of $1 \mu \mathrm{M} 5-\mathrm{HT}$ to the extracellular medium evoked a marked increase of the duration of the somatic spike (Fig. 2A, 5-HT). This effect appeared with a latency of 2-3 sec and was reversed by washing for 5-10 min. In cases in which the 5-HT application was maintained for more than $15 \mathrm{~min}$, no desensitization was observed.

\section{Action of 5-HT on the transmembrane currents}

Since we knew that in other identified molluscan neurons 5-HT increases $\mathrm{Ca}^{2+}$-dependent somatic spike by inducing a cAMPmediated decrease of $\mathrm{K}^{+}$conductance (as summarized in the introduction), we examined whether 5-HT induced a similar effect on the identified ventral parietal neurons. For this purpose, we voltage-clamped the neurons bathed in an extracellular medium containing $1 \mu \mathrm{M}$ TTX and $30 \mathrm{mM}$ TEA. The holding potential was set at $-50 \mathrm{mV}$, and the neurons were depolarized to $+20 \mathrm{mV}$ using $1 \mathrm{sec}$ current pulses. A composite current was then recorded, the initial inward component being followed by a large outward current (not illustrated). The inward current, as in other molluscan neurons (see Hagiwara and Byerly, 1981; Kostyuk, 1980), was $\mathrm{Ca}^{2+}$ dependent, while thc outward current corresponded to the different $\mathrm{K}^{+}$current components described in molluscan neurons, namely, $I_{\mathrm{DR}}$, the $\mathrm{K}^{+}$current associated with delayed rectification; $I_{\mathrm{A}}$, an early transient $\mathrm{K}^{+}$current; $I_{\mathrm{C}}$, 

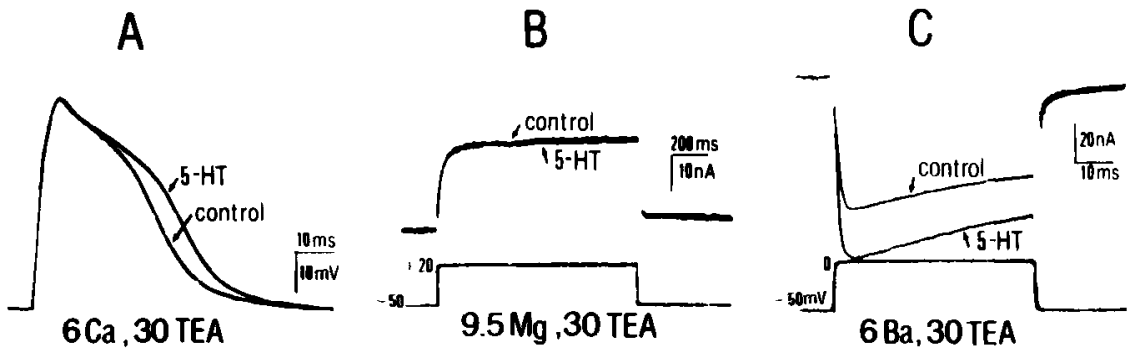

Figure 2. Effects of 5-HT on the action potential and the membrane currents of a D6 neuron. $A, 5-\mathrm{HT}$ increases the duration of the spike recorded in the cell body of a D6 neuron bathed in a saline containing $30 \mathrm{mM}$ TEA. Superimposed recordings of 2 action potentials, one recorded in the absence of 5-HT (control) and the other in the presence of $1 \mu \mathrm{M}$ 5-HT. B, Outward current recordings from a D6 cell bathed in an extracellular medium containing $30 \mathrm{~mm}$ TEA in which $\mathrm{Ca}^{2+}$ was replaced by $\mathrm{Mg}^{2+}$. The neuron was held at $-50 \mathrm{mV}$, and the voltage was stepped to $+20 \mathrm{mV}$ using $1 \mathrm{sec}$ pulses. The trace actually corresponds to 2 superimposed recordings of the outward current obtained in the absence and in the presence of $1 \mu \mathrm{M}$ 5-HT in the saline. $C$, Inward current recordings from the same D6 neuron as in $B$ bathed in TEA-containing saline in which Ca ${ }^{2+}$ was replaced with $\mathrm{Ba}^{2+}$. The cell, held at $-50 \mathrm{mV}$, was depolarized for $50 \mathrm{msec}$ to $0 \mathrm{mV}$. The application of $1 \mu \mathrm{M} 5-\mathrm{HT}$ evoked a $30 \%$ increase of the amplitude of the peak inward current.

the $\mathrm{Ca}^{2+}$-dependent $\mathrm{K}^{+}$current (see reviews, P. R. Adams, 1982; D. J. Adams et al., 1980); and perhaps the S current (Klein et al., 1982). Extracellular application of $1 \mu \mathrm{M} 5$-HT evoked both an apparent increase of the inward current and an apparent decrease of the outward current component.

In this situation, it was not possible to determine whether 5-HT acted either on the inward current, the outward current, or both. Therefore, to explore whether 5-HT evoked a decrease of the $\mathrm{S}$ current component in these neurons, we blocked both the inward and $\mathrm{Ca}^{2+}$-dependent $\mathrm{K}^{+}$currents. In this experiment (Fig. $2 B$ ) a D6 neuron was bathed in TEA-containing medium in which $\mathrm{Ca}^{2+}$ was replaced with $\mathrm{Mg}^{2+}$; the cell was held at -50 $\mathrm{mV}$ and depolarized to $+20 \mathrm{mV}$ by a $1 \mathrm{sec}$ pulse. The addition of $1 \mu \mathrm{M}$ 5-HT to the modified saline did not affect the outward current. (The recording of Fig. $2 B$ actually corresponds to 2 superimposed traces of the outward current obtained in the presence and in the absence of $1 \mu \mathrm{M}$ 5-HT in the bath.) It could then be concluded that after blocking the $\mathrm{Ca}^{2+}$ influx with $\mathrm{Mg}^{2+}$, 5-HT did not affect any TEA-insensitive outward current component of neuron D6.

As mentioned above, an important finding of the previous work on the 5-HT-induced decrease in $\mathrm{K}^{+}$current was the observation in the patch-clamp experiments of Siegelbaum et al. (1982) that in Aplysia sensory neurons held at membrane potentials near the zero level, the $\mathrm{K}^{+}$channels closed by 5-HT (called the $\mathrm{S}$ channels) constituted the main population of open channels. The closing of these 5-HT-sensitive channels may

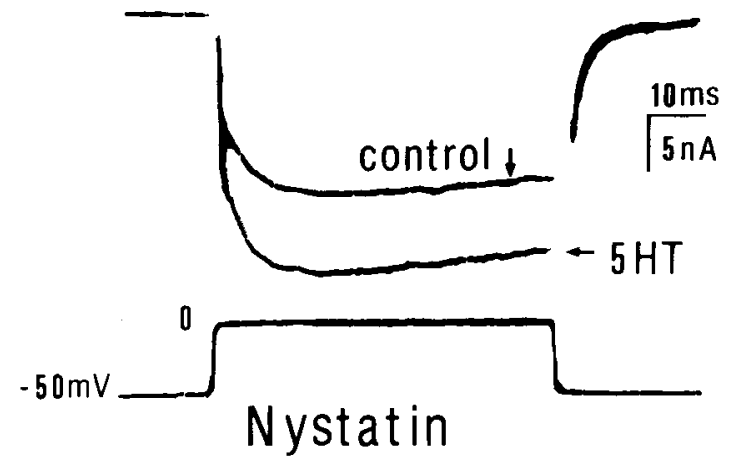

Figure 3. Persistence of the 5-HT-induced increase of inward current in a D6 neuron loaded with $\mathrm{Cs}^{+}$using nystatin treatment (see Materials and Methods). After complete washout of nystatin, the neuron was bathed in a saline solution in which $\mathrm{K}^{+}$was replaced with $\mathrm{Cs}^{+}, \mathrm{Na}^{+}$ with Tris, and $\mathrm{Ca}^{2+}$ with $\mathrm{Ba}^{2+}$. The intracellular microelectrodes contained $1 \mathrm{M} \mathrm{CsCl}$. account for the observation in a group of identified snail neurons (e.g., E13 and F1) voltage-clamped at +10 or $+20 \mathrm{mV}$ of a 5-HT-induced inward current resulting from a cAMP-dependent decrease in a $\mathrm{K}^{+}$conductance (Deterre et al., 1981, 1982; Paupardin-Tritsch et al., 1981). In contrast, when the membrane potential of any of the voltage-clamped identified ventral parietal neurons bathed either in normal saline or in $\mathrm{TEA} / \mathrm{Ba}^{2+}$ containing saline was held at $+20 \mathrm{mV}$, the application of $5-\mathrm{HT}$, even at $50 \mu \mathrm{M}$, did not evoke an inward current.

In view of these results we explored whether 5-HT would affect the inward current of the identified ventral parietal neurons. In Figure $2 C$ (control), the inward current through the $\mathrm{Ca}^{2+}$ channels was both separated from the other current components and facilitated by bathing neuron D6 in a saline solution containing both $1 \mu \mathrm{M}$ TTX and $30 \mathrm{~mm}$ TEA and in which $\mathrm{Ca}^{2+}$ was replaced with $\mathrm{Ba}^{2+}$. The cell was held at $-50 \mathrm{mV}$ and depolarized to $0 \mathrm{mV}$ by $50 \mathrm{msec}$ pulses. The application of 1

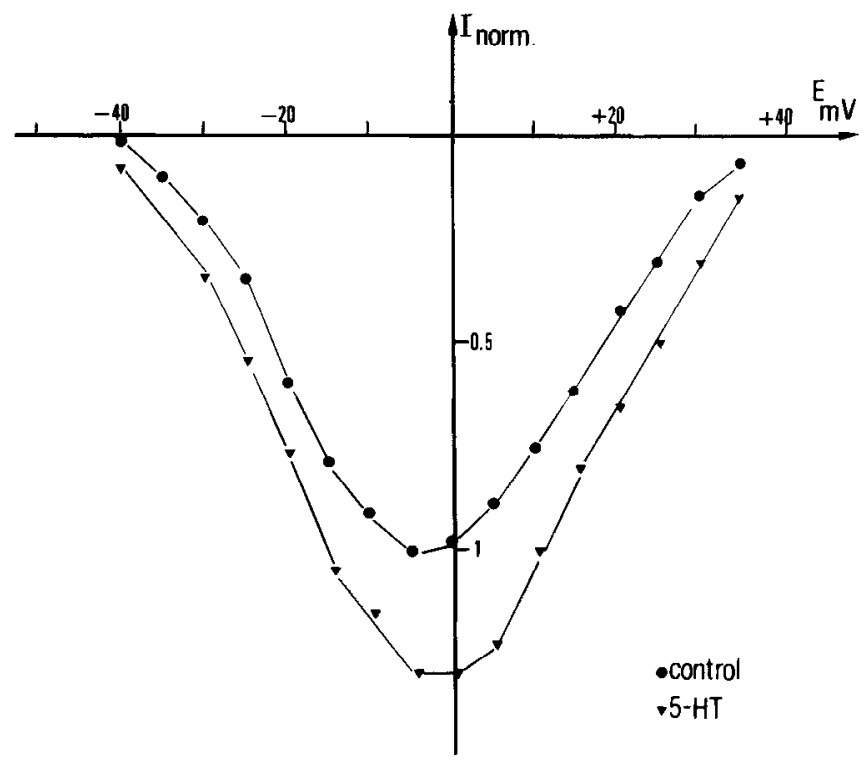

Figure 4. 5-HT effect on the $I-V$ curves obtained in a D6 neuron bathed in salinc containing $5 \mu \mathrm{M}$ TTX and $30 \mathrm{mM}$ TEA in which $\mathrm{Ca}^{2+}$ was replaced with $\mathrm{Ba}^{2+}$. The normalized values of the peak inward currents (in relation to 1 = maximal value of the inward current recorded in control saline) were obtained in the absence (circles) and in the presence (triangles) of $10 \mu \mathrm{M} 5-\mathrm{HT}$ and plotted against the values of the potential at which they were recorded. Both curves were corrected for linear leakage conductance. 


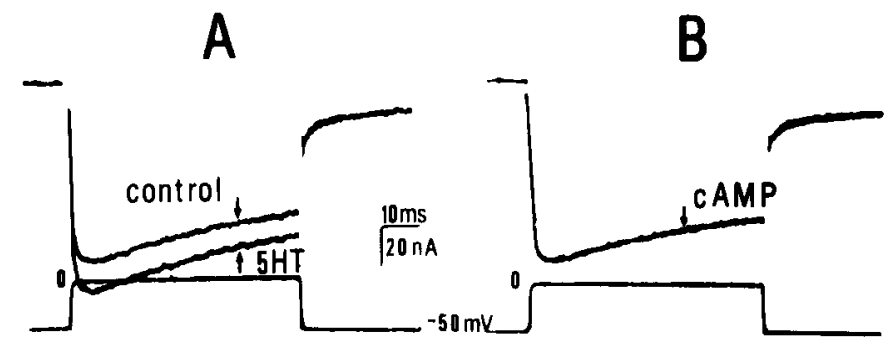

Figure 5. Inefficacy of cAMP. $A$, Inward current recorded in a D6 neuron bathed in a TTX/TEA/Ba ${ }^{2+}$-containing saline (control) was increased by $1 \mu \mathrm{M} 5$-HT. $B$, Intracellular injection of cAMP (100 msec iontophoretic pulses for $30 \mathrm{~min}$ at $0.5 \mathrm{~Hz}$ ) did not affect the inward current, the single trace corresponding to the current recordings before and after cAMP injection.

$\mu \mathrm{M} 5-\mathrm{HT}$ evoked a $30 \%$ increase in the amplitude of the inward current (Fig. 2C, 5-HT). It can then be concluded that 5-HT increased the inward current in cell D6. A similar 5-HT-induced increase of inward current was observed in neurons D7 and E1.

To confirm that 5-HT specifically increased the inward current through the $\mathrm{Ca}^{2+}$ channels, and at the same time to exclude a possible effect of 5-HT on a hidden outward current component, we performed another series of experiments using the antibiotic nystatin to exchange completely the intracellular $\mathrm{K}^{+}$ with $\mathrm{Cs}^{+}$(see Tillotson, 1979). Figure 3 illustrates one of these experiments, in which after incubating a D6 neuron in the $\mathrm{Cs}^{+}$loading solution containing nystatin for $20-30 \mathrm{~min}$, the antibiotic was removed and the neuron was finally bathed in a $\mathrm{Cs}^{+}$ containing Tris-saline in which $\mathrm{Ca}^{2+}$ was replaced with $\mathrm{Ba}^{2+}$ (see Materials and Methods). Under these conditions, in which $\mathrm{Cs}^{+}$was the only intracellular monovalent cation and both $\mathrm{K}^{+}$ and $\mathrm{Na}^{+}$were absent from the extracellular medium, the inward current was still markedly increased by application of $1 \mu \mathrm{M} 5-\mathrm{HT}$ (Fig. 3).

Another important argument in favor of the specificity of the effect of 5-HT on $\mathrm{Ca}^{2+}$ channels is given in Figure 4, which illustrates the $I-V$ curves relating the inward current amplitudes and the membrane potential at which they were recorded in a D6 neuron bathed in TTX/TEA/ $\mathrm{Ba}^{2+}$-containing saline. It can be observed that 5-HT elicited an increase of the inward current (triangles) throughout the membrane potential range explored. Moreover, the potential level at which the inward current became maximal in the presence or in the absence of $10 \mu \mathrm{M} 5-\mathrm{HT}$ was the same, and at this potential the inward current induced by 5 -HT was maximal.

Therefore, on the basis of all these results, it can be concluded that 5-HT increases the inward current of the identified ventral parietal neurons by increasing the $\mathrm{Ca}^{2+}$-membrane conductance.

\section{Intracellular mechanism of the 5-HT-induced increase of calcium current}

Different second messengers have been reported in the literature as being involved in the intracellular control of the inward cur-
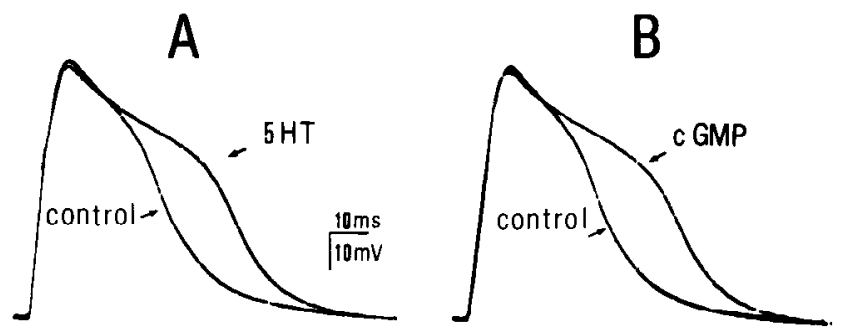

Figure 7. Increased duration of the $\mathrm{Ca}^{2+}$ action potential by cGMP. $A$, Bath application of $1 \mu \mathrm{M} 5-\mathrm{HT}$ to a D6 cell bathed in saline containing $30 \mathrm{~mm}$ TEA evoked a marked increase of the spike duration. The 2 superimposed action potentials were recorded in the absence and in the presence of 5-HT. $B$, In the same cell, intracellular pressure injection of cGMP evoked an increase of the $\mathrm{Ca}^{2+}$ spike duration similar to that induced by 5-HT.

rent in excitable cells: cAMP (see Reuter, 1983), cGMP (see Trautwein et al., 1982), $\mathrm{Ca}^{2+}$ (see Eckert and Tillotson, 1981; Tillotson, 1979), and probably diacylglycerol, by activating the enzyme protein kinase C (see DeRiemer et al., 1985). We then explored whether any of these intracellular messengers affected the 5-HT-induced increase of the inward current in the identified neurons.

\section{Intracellular cAMP}

In view of the aforementioned observations on cardiac muscle cells, we first analyzed the effects of the intracellular injection of cAMP on the somatic spike recorded in the identified ventral parietal neurons bathed in a TEA-containing saline. The cAMP injections affected neither the duration of the action potential (not illustrated) nor the inward current recorded in these cells (Fig. 5). Moreover, cAMP had no effect on their TEA-resistant outward currents (not shown). Another important argument against cAMP's intervention in the 5-HT-induced increase of the inward current is that the application of $20 \mu \mathrm{M}$ forskolin, a potent adenylate cyclase stimulating agent (Seamon and Daly, 1981; see also Deterre et al., 1982), altered neither the inward current (Fig. 6B) nor the 5-HT-induced increase of this current (Fig. 6C). It can be concluded that cAMP did not intervene in the 5-HT-induced increase of the inward current in the ventral parietal neurons.

\section{Intracellular cGMP}

In the next series of experiments, it was observed that unlike cAMP, cGMP mimicked the effects of 5-HT on the somatic action potential of the identified ventral neurons. Figure 7 illustrates one of these experiments performed on a D6 neuron bathed in TEA-containing saline in which 5-HT prolonged the spike duration (Fig. $7 A$ ). The intracellular injection of CGMP evoked an increase of the spike duration similar to that caused by 5 -HT (Fig. 7B). Voltage-clamp experiments showed that intracellular injection of cGMP did not affect any of the outward currents (not illustrated) but that it did increase the inward current. This is illustrated in Figure 8, which shows an exper-
Figure 6. Inefficacy of forskolin. $A$, Effect of 5-HT on the inward currents recorded in a D6 neuron bathed in a TTX/TEA $/ \mathrm{Ba}^{2+}$-containing saline. $B$, Single trace corresponding to the superimposed inward currents recorded in the presence and in the absence of $20 \mu \mathrm{M}$ forskolin in the bath. $C$, In the presence of forskolin, application of $1 \mu \mathrm{M}$ 5-HT still increased the inward current.

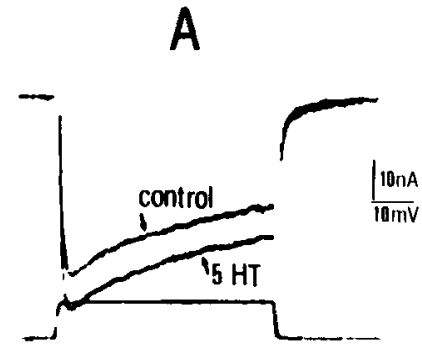

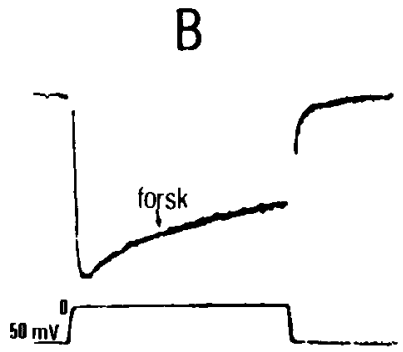

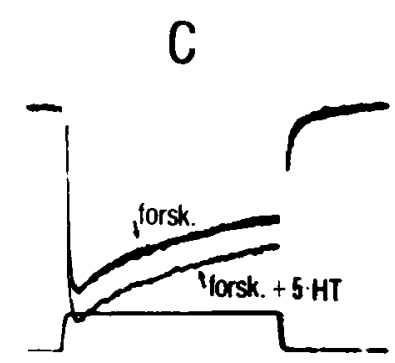




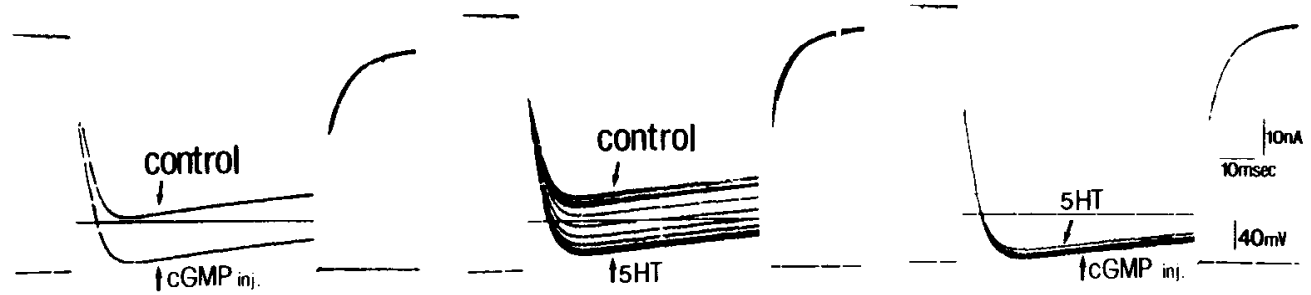

Figure 8. Comparison between the effects of 5-HT and cGMP on the inward current of the same D6 neuron. $A$, Inward current recordings in TTX/TEA/ $/ \mathrm{Ba}^{2+}$-containing saline. Intracellular pressure injection of cGMP evoked an increase of the inward current. $B$, Bath application of 10 $\mu \mathrm{M}$ 5-HT increased the inward current. The recording corresponds to many superimposed traces obtained during 5-HT application until the inward current attained its maximum effect. $C$, Immediately after $B$, repetitive intracellular injections of cGMP in the continued presence of 5-HT did not further increase the amplitude of the inward current.

iment on a D6 ncuron bathed in TTX/TEA/Ba ${ }^{2+}$-containing saline. The cell was held at $-50 \mathrm{mV}$ and depolarized to $0 \mathrm{mV}$ using $60 \mathrm{msec}$ pulses. The intracellular injection of cGMP markedly increased the inward current (Fig. 8A). The extracellular application of $1 \mu \mathrm{M} 5-\mathrm{HT}$ to the same cell evoked an increase of amplitude similar to that elicited by cGMP (Fig. $8 B$ ). When cGMP was injected intracellularly while the inward current was kept maximally increased by the presence of 5-HT in the bath, no further increase of the inward current occurred (Fig. 8C). Conversely, when cGMP induced a maximal increase of the inward current, application of 5-HT was ineffective.

The similarity between the effects of 5-HT and cGMP is further shown in the $I-V$ curves of Figure 9, which were obtained from the same D6 neuron as in Figure 4. The cell was bathed in TTX $/ \mathrm{TEA} / \mathrm{Ba}^{2+}$ saline, and these $I-V$ curves were obtained by relating the amplitude of the inward currents (after subtracting the leakage currents) to the membrane potentials at which the currents were recorded. It is clear that cGMP induced an increase of the inward current at all potentials examined. Moreover, the potential level at which the inward current became maximal both under control conditions and during cGMP injections was the same, with the cGMP effect becoming maximal at this potential. Therefore, we conclude that cGMP, as 5-HT, increased the inward current of the identified neurons by increasing $\mathrm{Ca}^{2+}$ membrane conductance.

We examined next whether the phosphodiesterase inhibitors that increase intracellular cGMP concentration in other cells induce a similar inward current increase in the ventral parietal neurons. Two different inhibitors of phosphodiesterases were tested: IBMX and zaprinast (see Winquist et al., 1984). We failed to observe any increase of the inward current after application of IBMX. Figure 10 shows that in a neuron in which 5-HT evoked an increase in the inward current (Fig. 10 $\mathrm{A}$ ), extracellular application of $200 \mu \mathrm{M}$ IBMX did not alter the inward current (Fig. 10B). Moreover, the presence of $200 \mu \mathrm{M}$ IBMX almost completely blocked the increase of the inward current induced by 5 -HT (Fig. 10C). In contrast, zaprinast did increase the inward current. Figure 11 presents the results of an experiment on a D6 neuron bathed in TTX/TEA/ $\mathrm{Ba}^{2+}$-containing saline in which $5 \mu \mathrm{M}$ 5-HT evoked an increase of the inward current (Fig. $11 A$ ). This effect was mimicked by the application of $100 \mu \mathrm{M}$ zaprinast (Fig. $11 B$ ). However, zaprinast was unable to potentiate the response of the same cell to a low concentration of 5-HT. As shown in Figure $11 C, 50 \mathrm{~nm}$ 5-HT evoked a small increase of the inward current, but when $1 \mu \mathrm{M}$ zaprinast, which by itself was without any effect on the inward current (Fig. 11D), was applied, it blocked the inward current increase induced by the low 5-HT concentration (Fig. $11 E$ ).

\section{Intracellular calcium}

The possibility that 5 -HT affects intracellular $\mathrm{Ca}^{2+}$ concentration was also examined by studying the effects of intracellularly injected EGTA on the inward current. As shown in Figure 12 a prolonged injection of EGTA into a D6 neuron did not affect the 5-HT-induced increase of the inward current. This finding suggests that the effect of 5-HT on the inward current is unrelated to the removal of the current inactivation that would result from a decrease of the intracellular $\mathrm{Ca}^{2+}$ concentration. To confirm that the cell loading with EGTA was effective, parallel experiments were carried out in which intracellular injections of EGTA were shown to block the $\mathrm{Ca}^{2+}$-dependent after-hyperpolarization that follows a train of spikes.

\section{Activation of protein kinase $C$}

DeRiemer et al. (1985) recently reported that intracellular injection of protein kinase $\mathrm{C}$ (a calcium/phosphatidylserine/diacylglycerol-dependent protein kinase) or stimulation of this enzyme by phorbol ester TPA evokes an increase of the inward current of the neuroendocrine bag cells of Aplysia. We therefore also explored whether phorbol ester TPA had a similar effect on the inward current of the identified ventral parietal snail

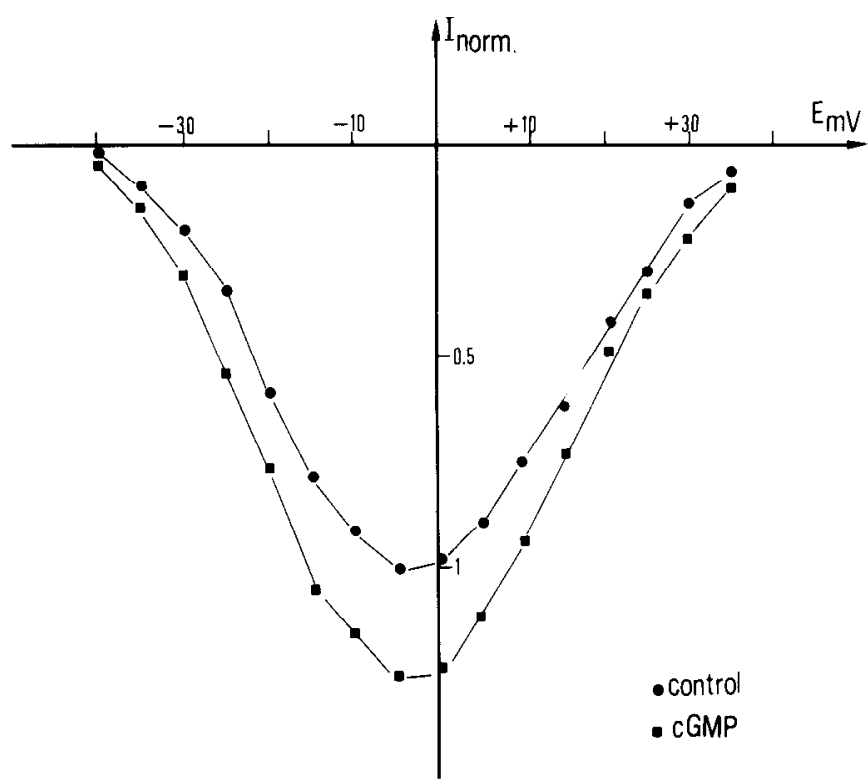

Figure 9. Effect of the intracellular pressure injection of cGMP on the $I-V$ curve obtained in a D6 neuron (same as in Fig. 4) bathed in TTX/ TEA-containing saline in which $\mathrm{Ca}^{2+}$ was replaced with $\mathrm{Ba}^{2+}$. The normalized peak values of the inward currents (in relation to $1=$ maximal value of the inward current in control saline) were plotted against the values of the membrane potential at which they were recorded, either before application of cGMP (circles) or after repeated intracellular pressure injections of cGMP (squares). Both curves were corrected for the linear leakage conductance. 
Figure 10. Effect of IBMX on the inward current of a $D 6$ neuron bathed in TTX/TEA/ $/ \mathrm{Ba}^{2+}$-containing saline. $A, 5$-HT-induced enhancement of the inward current. $B$, Application of 200 $\mu \mathrm{M}$ IBMX does not affect the inward current, the trace corresponding to 2 superimposed recordings of the inward current in the absence and in the presence of 5-HT. C. Presence of 200 $\mu \mathrm{M}$ IBMX in the bath blocks the effect of 5-HT on the inward current.
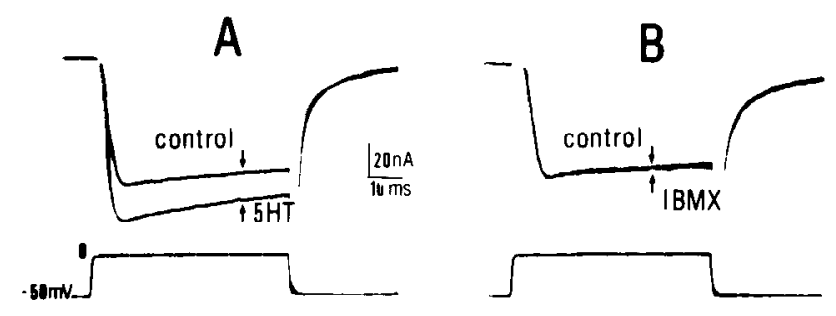

neurons. Figure 13 illustrates one of these experiments on a D6 neuron in which 5-HT evoked an increase of the inward current. Application of $100 \mathrm{~nm}$ phorbol ester TPA to this neuron also evoked an apparent increase of the inward current, which was accompanied by an alteration of the time course of the current: The increase was very small at the peak, and it was much larger at the end of the pulse. Therefore, phorbol ester TPA appears to reduce the inward current inactivation (Fig. 13B). Moreover, 5-HT reapplied in the continued presence of phorbol ester TPA still increased the inward current by a similar amplitude as the control effect (Fig. 13B), but phorbol ester TPA's effect on the current persisted.

\section{Discussion}

\section{The 5-HT-induced increase in calcium conductance}

The results of our experiments on the identified ventral parietal neurons indicate that the increase in duration of their somatic $\mathrm{Ca}^{2+}$ action potential is due to an inward current enhancement resulting from an increase in membrane $\mathrm{Ca}^{2+}$ conductance. Under the conditions of these experiments -i.e., replacement of the extracellular $\mathrm{Ca}^{2+}$ by $\mathrm{Ba}^{2+}$ and addition of TEA to the extracellular medium in all the experiments and of 4-AP in many of them-it seems unlikely that the 5-HT-induced increase of the inward current was only apparent and that it was, instead, depressing an outward current component. An alternative explanation for the effects of 5-HT is that the inward current increases because of an increase in $\mathrm{Na}^{+}$conductance. These possibilities were ruled out by our experiments on nystatintreated, $\mathrm{Cs}^{+}$-loaded neurons. In these cells, bathed in a medium in which $\mathrm{Na}^{+}$was replaced with Tris and $\mathrm{K}^{+}$by $\mathrm{Cs}^{+}$, no outward current persisted; thus, the sole effect of 5-HT could have been to increase the inward current through the $\mathrm{Ca}^{2+}$ channels. In addition, the $I-V$ curves shown in Figure 4 confirm that 5 -HT acted by inducing an increase in $\mathrm{Ca}^{2+}$ membrane conductance.
Intracellular mechanism of the 5-HT-induced increase of the calcium current

Our efforts to identify the second messenger mediating the 5-HTinduced increase of the $\mathrm{Ca}^{2+}$ current of the ventral parietal neurons allowed us at least to rule out the participation of some known intracellular messengers.

1. Intervention by cAMP can be excluded since both the prolonged intracellular injection of cAMP and bath application of forskolin, a potent stimulator of adenylate cyclase, were totally ineffective on the action potential and the inward current of the ventral parietal neurons.

2. Participation of intracellular $\mathrm{Ca}^{2+}$ can also be excluded, since loading the neurons with EGTA did not affect the increase of inward current induced by 5-HT.

3. It can also be almost excluded that the 5-HT-induced increase of inward current resulted from stimulation of the enzyme protein kinase $\mathrm{C}$ via the formation of diacylglycerol (see for reviews Berridge, 1984; Nishizuka, 1984). Intracellular injection of protein kinase $\mathrm{C}$ and application of phorbol ester TPA, an agonist of diacylglycerol that stimulates protein kinase $\mathrm{C}$, both increase the $\mathrm{Ca}^{2+}$ current of some molluscan neurons (DeRiemer et al., 1985). However, our experiments showed that TPA applied at the same concentrations used by DeRiemer et al. elicited an apparent increase of the inward current of the identified snail ventral parietal neurons; however, this action differed from that of 5-HT: The main effect of phorbol ester TPA was to cause an apparent depression of the $\mathrm{Ca}^{2+}$-current inactivation, which 5 HT did not affect. Therefore, the effects of these 2 agents seem to be independent, and it can be concluded that these observations do not support the idea of a direct involvement of diacylglycerol and protein kinase $\mathrm{C}$ in the 5-HT-induced increase of $\mathrm{Ca}^{2+}$ current.

In contrast, our experiments favor a role for $\mathrm{cGMP}$ as a second messenger generating the 5-HT-induced $\mathrm{Ca}^{2+}$ current. Intracel-
Figure 11. Effect of zaprinast on the inward current of a D6 neuron bathed in TTX/TEA $/ \mathrm{Ba}^{2+}$-containing saline. $A$, Enhancement of the inward current by $1 \mu \mathrm{M}$ 5-HT. $B$, Amplitude of control inward current was slightly reduced after washing out the amine, but $100 \mu \mathrm{M}$ zaprinast evoked increased amplitude of the inward current. $C$, In a different D6 neuron bathed in the same saline, application of $50 \mathrm{~nm} 5$-HT evoked a small increase of inward current. $D$, After washing out 5-HT, application of 1 $\mu \mathrm{M}$ zaprinast had no effect on the inward current (superimposed recordings). $E$, In the continuous presence of $1 \mu \mathrm{M}$ zaprinast, the response to application of $50 \mathrm{nM} 5-\mathrm{HT}$ was abolished.
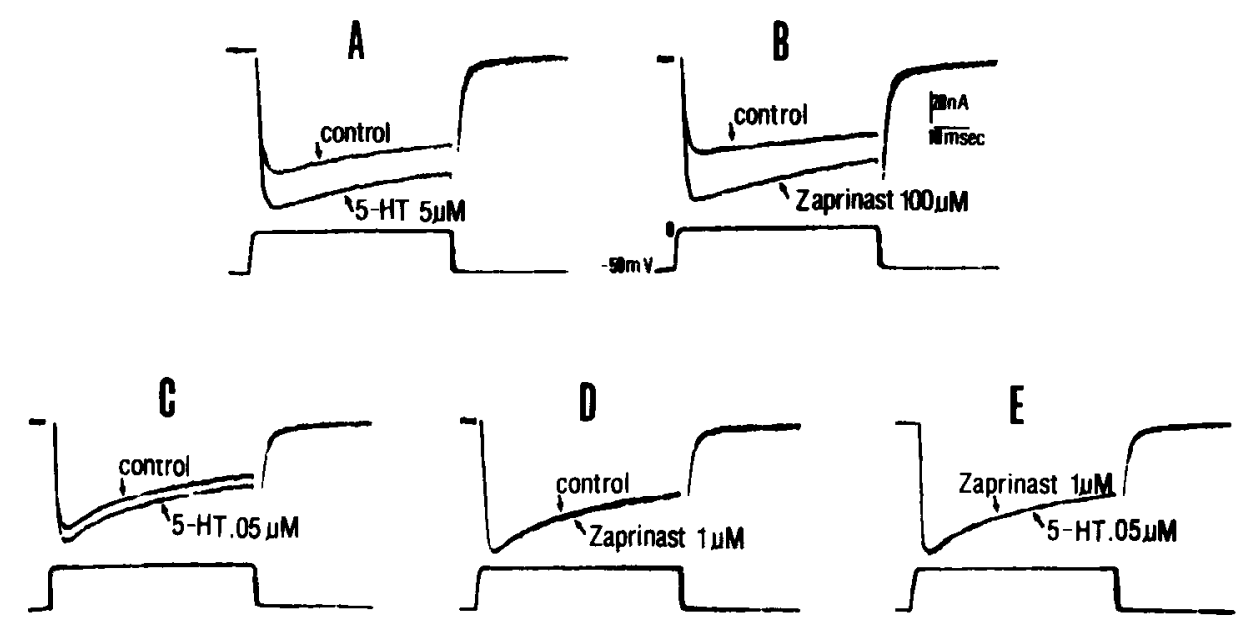


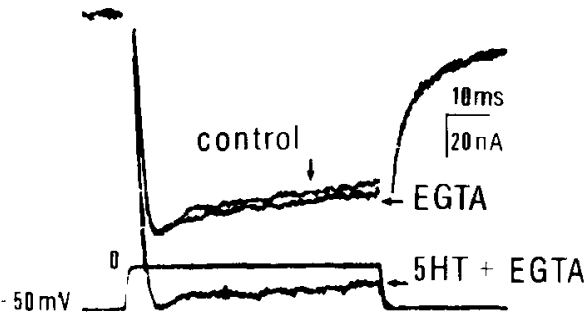

Figure 12. Intracellular pressure injection of EGTA in cell D4 bathed in a TTX/TEA/Ba ${ }^{2+}$-containing saline. After injecting EGTA intracellularly for $30 \mathrm{~min}$, the amplitude of the inward current was slightly increased, and application of $1 \mu \mathrm{M} 5-\mathrm{HT}$ evoked an increase of the inward current similar to the effect recorded before EGTA injection.

lular injection of cGMP or zaprinast-induced increase in intracellular cGMP (see Winquist et al., 1984) had effects similar to those of 5-HT. Moreover, the maximal effects of cGMP and 5-HT on the inward current were not additive, i.e., when one of these agents induced a maximal increase of the inward current, application of the other bccame incffective. This finding suggests that 5-HT and cGMP act on the same $\mathrm{Ca}^{2+}$-channel population through the same chain of metabolic events involved in increasing the inward current. However, we cannot account for either the lack of effect of IBMX or of zaprinast's blocking of the 5-HT responses at low concentrations, rather than potentiating them. It is possible that zaprinast may exert some blocking action on the 5-HT receptors.

It has been recently proposed that stimulation of cGMP formation may involve activation of receptors that trigger increased hydrolysis of phosphoinositides (see Berridge, 1984; Nishizuka, 1984; Snider et al., 1984). These receptors would activate guanylate cyclase indirectly by releasing arachidonic acid, which, converted to another metabolite, would stimulate the synthesis of cGMP. Intracellular $\mathrm{Ca}^{2+}$ seems to be necessary to release arachidonic acid (see Berridge, 1984). If cGMP is the second messenger affecting the 5-HT-induced $\mathrm{Ca}^{2+}$ current, then an arachidonic acid cascade may not necessarily be involved, since the intracellular injection of EGTA did not alter the effects of 5-HT.

\section{Multiplicity of transmitters, receptors, and second messengers modulating the calcium current}

As already indicated in the introduction, beta-adrenergic agonists increase the $\mathrm{Ca}^{2+}$ current of cardiac muscle cells by a mechanism involving an intracellular mediation by cAMP, whereas $\mathrm{ACh}$ and muscarinic agonists decrease the $\mathrm{Ca}^{2+}$ current, an effect possibly mediated by cGMP (see for reviews Reuter, 1983; Tsien, 1983).

In neurons, the modulatory effect of neurotransmitters on the $\mathrm{Ca}^{2+}$ current that has been most frequently reported is a decrease of this current. Thus, noradrenaline decreases the $\mathrm{Ca}^{2+}$ current of both sympathetic neurons (Galvan and Adams, 1982; Horn and McAffee, 1980; McAffee et al., 1981) and cultured embryonic spinal ganglion neurons (Dunlap and Fischbach, 1980). GABA, 5-HT, and enkephalin also decrease the $\mathrm{Ca}^{2+}$ current of the latter neurons (Dunlap and Fischbach, 1980), and dopamine and the peptide FMRF amide decrease the $\mathrm{Ca}^{2+}$ current of some identified snail neurons (Colombaioni et al., 1983; Paupardin-Tritsch et al., 1985b).

The work of Pellmar (1984) and the present work are among the first to describe a transmitter-induced increase of $\mathrm{Ca}^{2+}$ current in neurons. Pellmar (1984) reported that 5-HT increased the inward current of the RB neurons of $A$. californica bathed in a TEA/4-AP/ $/ \mathrm{Ba}^{2+}$-containing medium. The main difference between Pellmar's results and our own is that when the Aplysia RB cells were voltage-clamped at $-20 \mathrm{mV}, 5-\mathrm{HT}$ also evoked a slow inward current, which was mimicked by cAMP (see Pellmar, 1981). As in previous papers (Pellmar and Carpenter, 1979, 1980), Pellmar interpreted this 5-HT-induced inward current as also resulting from an increase in $\mathrm{Ca}^{2+}$ conductance. We do not share this interpretation for the following reasons.

1. In the present experiments, 5-HT induced an increase in $\mathrm{Ca}^{2+}$ current in the identified ventral parietal neurons, but when these neurons were clamped at potentials between -20 and +20 $\mathrm{mV}$, either in normal saline or in TEA $/ \mathrm{Ba}^{2+}$ saline, no 5-HTinduced current was observed.

2. In contrast, in identified snail neurons other than the ventral parietal cells (E13, F1; see Deterre et al., 1981, 1982) in which both 5-HT and DA also increased the duration of the somatic $\mathrm{Ca}^{2+}$ spike (Paupardin-Tritsch et al., 1981, 1985b), these transmitters evoked a slow inward current with characteristics similar to those observed by Pellmar (1984); also, this effect was mimicked by cAMP. In these snail neurons, no change in the $\mathrm{Ca}^{2+}$ current was observed. Instead, both the 5-HT- and dopamineinduced slow inward currents were shown to result from a decrease of a cAMP-dependent $\mathrm{K}^{+}$conductance. Moreover, when these neurons were held at the resting potential and depolarized by short current pulses, 5-HT and dopamine also decreased the S current, i.e., the cAMP-dependent $\mathrm{K}^{+}$current component (see Klein et al., 1982; Paupardin-Tritsch et al., 1985b).

3. In some other identified neurons of $H$. aspersa (namely, F5; Paupardin-Tritsch et al., 1985a, b, and unpublished observations) in which 5-HT and dopamine evoked a slow inward current and a decrease of the $\mathbf{S}$ current, these transmitters actually decreased, rather than increased, the $\mathrm{Ca}^{2+}$ current.

From these facts we conclude that Pellmar's observation in the RB neurons of both a 5-HT-induced increase of inward current (probably $\mathrm{Ca}^{2+}$ current) and a slow inward current when the cells are held around $0 \mathrm{mV}$ does not necessarily imply that the same ionic mechanism is responsible for both effects. In contrast, these 2 effects of 5-HT could probably be mediated by different, independent mechanisms: on one hand, an increase

\section{A}

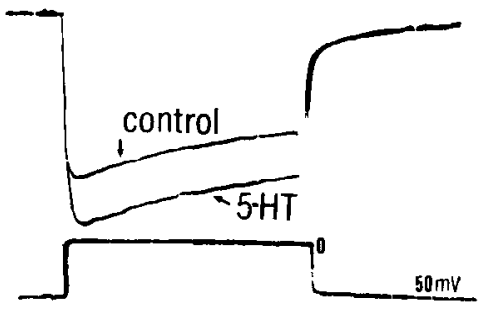

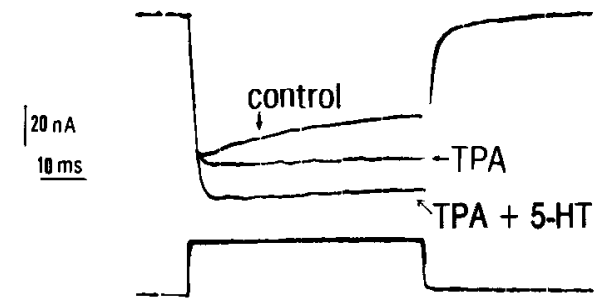

Figure 13. Effect of phorbol ester TPA on the inward current of a D6 neuron bathed in TTX/TEA $/ \mathrm{Ba}^{2+}$. containing saline. $A, 5$-HT-induced enhancement of the inward current. $B$, Application of $100 \mathrm{~nm}$ TPA evoked an apparent increase of the inward current. This increase was uneven, and the peak current enhancement was slight while the amplitude of the current at the end of the pulse increased markedly. In the continuous presence of TPA, 5-HT evoked an increase of the inward current without altering the TPA-induced depression of the current inactivation. 
in the $\mathrm{Ca}^{2+}$ current and, on the other, a decrease in a $\mathrm{K}^{+}$conductance gated by cAMP. This multiplicity of the effects of 5-HT is not surprising, since, as previously shown (see Gerschenfeld et al., 1981), molluscan neurons arc endowed with multiple receptors for 5-HT, and many of them may coexist on the membrane of a single neuron. On the basis of the findings reviewed above, it can also be concluded that a transmitter can induce different mechanisms involved in the modulation of the $\mathrm{Ca}^{2+}$ action potential and that these mechanisms may coexist in a single cell.

Finally, it is interesting to emphasize that the second messengers mediating the modulation of the $\mathrm{Ca}^{2+}$ current also display multiple effects. Thus, whereas in cardiac muscle cells, cAMP mediates an increase of $\mathrm{Ca}^{2+}$ current and cGMP is supposed to intervene in a transmitter-induced decrease of the $\mathrm{Ca}^{2+}$ current, in identified molluscan neurons, cAMP mediates a decrease in $\mathrm{K}^{+}$conductance and $\mathrm{cGMP}$, as shown here, may be involved, either directly or indirectly, in a 5-HT-induced increase of the $\mathrm{Ca}^{2+}$ current.

\section{References}

Abrams, T. W., V. F. Castellucci, J. S. Camardo, E. R. Kandel, and P. E. Lloyd (1984) Two endogenous peptides modulate the gill and siphon withdrawal refiex in Aplysia by presynaptic facilitation involving cAMP-dependent closure of a serotonin-sensitive channel. Proc. Natl. Acad. Sci. USA 81: 7956-7960.

Adams, D. J., S. J. Smith, and S. H. Thompson (1980) Ionic currents in molluscan neurones. Annu. Rev. Neurosci. 3: 141-167.

Adams, P. R. (1982) Voltage-dependent conductances of vertebrate neurones. Trends Neurosci. 46: 116-119.

Bean, B. P., M. C. Nowycky, and R. W. Tsien (1984) $\beta$-Adrenergic modulation of calcium channels in frog ventricular heart cells. Nature 307: 371-375.

Berridge, M. J. (1984) Inositol triphosphate and diacylglycerol as second messengers. Biochem. J. 220: 345-360.

Boyle, M. B., M. Klein, S. J. Smith, and E. R. Kandel (1984) Serotonin increases intracellular $\mathrm{Ca}^{2+}$ transients in voltage clamped sensory neurons of Aplysia californica. Proc. Natl. Acad. Sci. USA 81: 76427646.

Brum, G., V. Flockerzi, F. Hofman, W. Osterrieder, and W. Trautwein (1983) Injection of catalytic subunit of cAMP-dependent protein kinase into isolated myocytes. Pfluegers Arch. 398: 146-154.

Brum, G., W. Osterrieder, and W. Trautwein (1984) $\beta$-Adrenergic increase in the calcium conductance of cardiac myocytes studied with the patch-clamp. Pfluegers Arch. 401: 111-118.

Byerly, L., and S. Hagiwara (1982) Calcium currents in internally perfused nerve cell bodies of Lymnaea stagnalis. J. Physiol. (Lond.) 322: 503-528.

Castellucci, V. F., E. R. Kandel, J. H. Schwartz, F. D. Wilson, A. C. Nairn, and P. Greengard (1982) Intracellular injection of the catalytic unit of cyclic AMP-dependent protein kinase stimulates facilitation of transmitter release underlying behavioral sensitization. Proc. Natl. Acad. Sci. USA 77: 7492-7496.

Colombaioni, L., D. Paupardin-Tritsch, P. P. Vidal, and H. M. Gerschenfeld (1985) The neuropeptide FMRF amide decreases both the $\mathrm{Ca}^{2+}$-conductance and a cAMP-dependent $\mathrm{K}^{+}$-conductance in identified snail neurons. J. Neurosci. 5: 2533-2538.

DeRiemer, S. A., J. A. Strong, K. A. Albert, O. Greengard, and L. K Kaczmarek (1985) Enhancement of calcium current in Aplysia neurones by phorbol ester and protein kinase C. Nature 313: 313-316.

Deterre, P., D. Paupardin-Tritsch, J. Bockaert, and H. M. Gerschenfield (1981) Role of cyclic AMP in a serotonin-evoked slow inward current in snail neurones. Nature 290: 783-785.

Deterre, P., D. Paupardin-Tritsch, J. Bockaert, and H. M. Gerschenfeld (1982) cAMP-mediated decrease in $\mathrm{K}^{+}$conductance evoked by serotonin and dopamine in the same neuron: $A$ biochemical and physiological single-cell study. Proc. Natl. Acad. Sci. USA 79: 7934-7938.

Dunlap, K., and G. D. Fischbach (1980) Neurotransmitters decrease the calcium conductance activated by depolarization of embryonic chick sensory neurones. J. Physiol. (Lond.) 317: 519-535.

Eckert, R., and D. Tillotson (1981) Calcium-mediated inactivation of the calcium conductance in cesium-loaded giant neurones of Aplysia californica. J. Physiol. (Lond.) 314: 265-280.
Galvan, M., and P. R. Adams (1982) Control of calcium current in rat sympathetic neurons by norepinephrine. Brain Res. 244: 135144.

Gerschenfeld, H. M., P. Deterre, and D. Paupardin-Tritsch (1981) Neuronal responses to serotonin, a second view. In Serotonin Neurotransmission and Behavior, B. L. Jacobs and A. Gelperin, eds., pp. 105-130, MIT Press, Cambridge, MA.

Hagiwara, S., and L. Byerly (1981) Calcium channel. Annu. Rev. Neurosci. 4: 69-125.

Horn, J. P., and D. A. McAfee (1980) Alpha adrenergic inhibition of calcium-dependent potentials in rat sympathetic neurones. J. Physiol. (Lond.) 301: 109-204.

Kaczmarek, I. K., K. R. Jennings, F. Strumwasser, A. C. Nairn, A. C. Walter, and P. Greengard (1980) Microinjection of catalytic subunit of cAMP-dependent protein kinase enhances calcium action potentials of bag cell neurons in cell culture. Proc. Natl. Acad. Sci. USA 77: 7487-7491.

Kerkut, G. A., J. D. C. Lambert, R. J. Gayton, J. E. I oker, and R. J. Walker (1975) Mapping of nerve cells in the suboesophageal ganglia of Helix aspersa. Comp. Biochem. Physiol. 50A: 1-25.

Klein, M., and E. R. Kandel (1978) Presynaptic modulation of voltage dependent $\mathrm{Ca}^{2+}$ current: Mechanism for behavioral sensitization in Aplysia californica. Proc. Natl. Acad. Sci. USA 75: 3512-3516.

Klein, M., and E. R. Kandel (1980) Mechanism of calcium current modulation underlying presynaptic facilitation and behavioral sensitization in Aplysia. Proc. Natl. Acad. Sci. USA 77: 6912-6916.

Klein, M., J. S. Camardo, and E. R. Kandel (1982) Serotonin modulates a new potassium current in the sensory neurons that show presynaptic facilitation in Aplysia. Proc. Natl. Acad. Sci. USA 79: 5713-5717.

Kostyuk, P. G. (1980) Calcium ionic channels in electrically excitable membrane. Neuroscience 5: 945-959.

McAfee, D. A., B. K. Henon, J. P. Horn, and P. Yarowsky (1981) Calcium currents modulated by adrenergic receptors in sympathetic neurons. Fed. Proc. 40: 2246-2249.

Nishizuka, N. (1984) Turnover of inositol phospholipids and signal transduction. Science 225: 1365-1370.

Osterrieder, W., G. Brum, J. Hescheler, W. Trautwein, V. Flockerzi, and F. Hofmann (1982) Injection of subunits of cyclic AMP-dependent protein kinase into cardiac myocytes modulates $\mathrm{Ca}^{2+}$ current. Nature 298: 576-578.

Paupardin-Tritsch, D., P. Deterre, and H. M. Gerschenfeld (1981) Relationship between two voltage-dependent serotonin responses of molluscan neurones. Brain Res. 217: 201-206.

Paupardin-Tritsch, D., C. Hammond, and H. M. Gerschenfeld (1985a) A serotonin-induced increase of calcium current in identified molluscan neurons mimicked by cGMP but not by cAMP. Soc. Neurosci. Abstr. 11: 466.

Paupardin-Tritsch, D., L. Colombaioni, P. Deterre, and H. M. Gerschenfeld (1985b) Two different mechanisms of calcium spike modulation by dopamine. J. Neurosci. 5: 2522-2532.

Pellmar, T. C. (1981) Does 3'5'adenosine monophosphate act as a second messenger in a voltage-dependent response to 5-hydroxytryptamine in Aplysia? Br. J. Pharmacol, 74: 747-756.

Pellmar, T. C. (1984) Enhancement of inward current by serotonin in neurons of Aplysia. J. Neurobiol. 15: 13-25.

Pellmar, T. C., and D. O. Carpenter (1979) Voltage-dependent calcium current induced by serotonin. Nature 277 : 483-484.

Pellmar, T. C., and D. O. Carpenter (1980) Serotonin induces a voltage-sensitive calcium current in neurons of Aplysia californica. $\mathrm{J}$. Neurophysiol. 44: 423-439.

Reuter, H. (1983) Calcium channel modulation by neurotransmitters, enzymes and drugs. Naturc $301 ; 569-574$.

Reuter, H., and H. Scholz (1977) The regulation of the calcium conductance of cardiac muscle by adrenaline. J. Physiol. (Lond.) 264: $49-62$.

Reuter, H., A. B. Cachelin, J. E. De Peyer, and S. Kobuku (1983) Modulation of calcium channels in cultured cardiac cells by isoproterenol and 8-bromo-cAMP. Cold Spring Harbor Symp. Quant. Biol. 48: $193-200$.

Seamon, K. B., and J. W. Daly (1981) Forskolin: Unique diterpene activator of cyclic AMP generating system. J. Cyclic Nucleotide Res. 7: 201-224

Shuster, M. J., J. S. Camardo, S. A. Siegelbaum, and E. R. Kandcl (1985) Cyclic AMP-dependent protein kinase closes the serotonin- 
sensitive $\mathrm{K}^{+}$channels of Aplysia sensory neurones in cell-free membrane patches. Nature 313: 392-395.

Siegelbaum, S., J. S. Camardo, and E. R. Kandel (1982) Serotonin and cyclic AMP close single $\mathrm{K}^{+}$channels in Aplysia sensory neurones. Nature 299: 413-417.

Snider, R. M., M. McKinney, C. Forray, and E. Richelson (1984) Neurotransmitter receptors mediate cyclic GMP formation by involvement of arachidonic acid and lipoxygenase. Proc. Natl. Acad. Sci. USA 81: 3905-3909.

Tillotson, D. (1979) Inactivation of $\mathrm{Ca}^{2+}$-conductance dependent on entry of $\mathrm{Ca}^{2+}$-ions in molluscan neurones. Proc. Natl. Acad. Sci. USA 76: $1497-1500$.

Trautwein, W. J., Taniguchi, and A. Noma (1982) The effects of intracellular cyclic nucleotide and calcium on the action potential and acetylcholine response of isolated cardiac cells. Pflügers Arch. 392. 307-314.

Tsien, R. W. (1977) Cyclic AMP and contractile activity in the heart. Adv. Cyclic Nucleotide Res. 8: 363-420.

Tsien, R. W. (1983) Calcium channels in excitable cell membranes. Annu. Rev. Physiol. 45: 341-358.

Vassort, G., O. Rougier, D. Garnier, M. P. Sauviat, E. Coraboeuf, and Y. M. Gargouil (1969) Effects of adrenaline on inward membrane currents during the action potential. Pfluegers Arch. 309: 70-81.

Winquist, R. J., E. P. Faison, S. A. Waldman, K. Schwartz, F. Murad, and R. M. Rapport (1984) Atrial natriuretic factor elicits an endothelium-independent relaxation and activates particulate guanylate cyclase in vascular smooth muscle. Proc. Natl. Acad. Sci. USA 81 . 7661-7664. 